\title{
Characterization of a-Si:H thin films prepared by dc glow tischarage of silane
}

\author{
D S MISRA, P N DIXIT and S C AGARWAL \\ Department of Physics, Indian Institute of Technology, Kanpur 208 016, India
}

MS received 28 June 1981

\begin{abstract}
A dc glow discharge apparatus for preparing amorphous silicon films from silane gas is described. The films are characterized by electron microscopy, infrared spectroscopy, electrical conductivity and photoconductivity. The deposition parameters which give good photoconducting films are established. The Stacbler-Wronski effect is studied and is found to be smaller in vacuum than in air. A photovoltage is observed in structures with gold as the Schottkybarrier metal. The conversion efficiency of the device is about $1 \%$. The results are compared with those in the literature, and the improvements which might result in a better conversion efriciency are pointed out.
\end{abstract}

Keywords. Characterization; glow discharge; amorphous silicon; thin film; silane.

\section{Introduction}

Thin films of a-Si:H prepared under suitable conditions by the glow discharge of silane $\left(\mathrm{SiH}_{4}\right)$ are found to have desirable electrical and optical properties. These films can be doped n-type or $p$-type because they have lesser number of localized states in the mobility gap as compared to a-Si prepared by other methos's (Spear and Le Comber 1975). This reduction in the number of localized states is attributed to the presence of hydrogen in the lattice (Brodsky et al 1977), which compensates the dangling bonds. But the amount of hydrogen in the lattice is about $10-35$ at. \% which is $\sim 100$ times more than the dangling bonds observed in the case of evaporated a-Si. Thus it is believed (Fritzsche et al 1978) that it is not only the compensation of dangling bonds but also the modification of the structure because of the presence of hydrogen which is responsible for the interesting properties of a-Si: $\mathrm{H}$.

We report the design of a de glow discharge apparatus fabricated in our laboratory. The structural characterization of a-Si:H by electron microscopy and IR spectroscopy is also reported. The IR spectra shows the presence of hydrogen in our films. Electrical characterization of the samples is done by studying the dark conductivity and photoconductivity as a function of temperature. A photovoltage $\left(\mathrm{V}_{\mathrm{O}_{\mathrm{O}}}\right) \approx 350 \mathrm{mV}$ is observed in sandwich structures of $\mathrm{NiCr} / \mathrm{a}-\mathrm{Si}: \mathrm{H} / \mathrm{Au}$ (top), upon shining white light (flux $=5 \times 10^{14}$ photons $/ \mathrm{cm}^{2} / \mathrm{sec}$ ). After exposing to AMI light for about $4 \mathrm{hr}$ the room temperature conductivity decreases. This effect is found to be more in air than in vacuum by about an 
order of magnitude. In both the cases, however, the magnitude of the change in room temperature conductivity upon exposing to light is much smaller in our films than reported in the literature (Staebler and Wronski 1977). The results are presented in $\S 2.3 \mathrm{c}$. Finally, these results are discussed in $\S 3$.

\section{Experimental}

\section{$2 \cdot 1$ Details of the glow discharge apparatus}

A mixture $3 \%$ silane and $97 \%$ argon is subjected to a dc electric field in a glow discharge reaction chamber of pyrex glass shown in figure 1. A capacitor geometry is used for the discharge. The diameter and length of the reaction chamber are 16 and $20 \mathrm{~cm}$ respectively. An aluminium plate of $10 \mathrm{~cm}$ diameter is used as anode and an aluminium screen as cathode. The screen is used to overcome the difficulties associated with the charging of glass substrates during the discharge. The substrates are kept about $1 \mathrm{~cm}$ away from the screen on another stainless steel plate which contains a heater and can be heated up to $500^{\circ} \mathrm{C}$.

Since silane is highly reactive the gas mixture is first filled in an auxiliary cylinder at a pressure of about $3-6 \times 10^{3} \mathrm{~kg} / \mathrm{m}^{2}$, to minimize the danger. The mixture is let into the reaction chamber through a needle valve which controls the flow. The system is constantly pumped by a rotary pump and a pressure of about 1 torr is maintained during the discharge. The gases coming out of the reaction chamber are passed through an oven kept at $\approx 1000^{\circ} \mathrm{C}$ to thermally decompose any silane which might escape the electric field. A magnetic isolation-cum-air-admittance valve is placed between the oven and the rotary pump and is connected in such a way that during an emergency, such as, a sudden power failure, the pump is isolated and the system is flooded with dry nitrogen

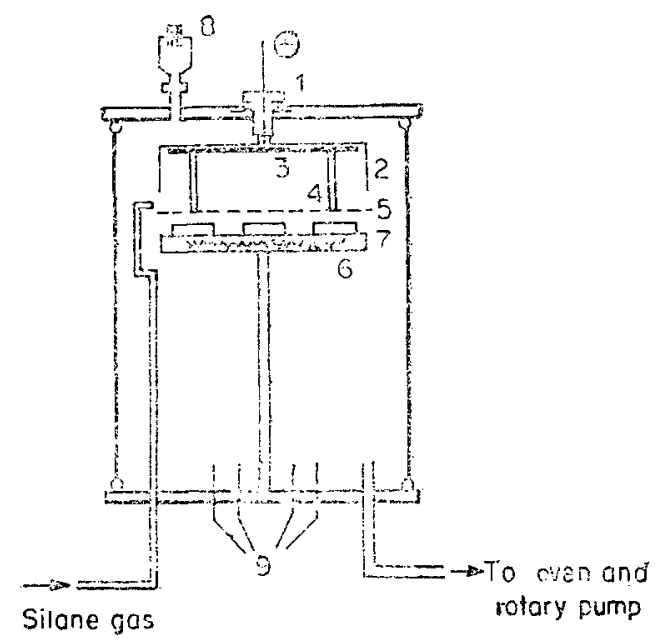

Figure 1. Glow discharge reaction chamber. 1. High tension feed through, 2. Pyrex anode shicld, 3. Anode, 4. Ceramic post, 5. Aluminium screen (Cathode), 6. Steel plate containing heater, 7. Substrates, 8. Thermocouple gauge, 9. Electrical feed through. 


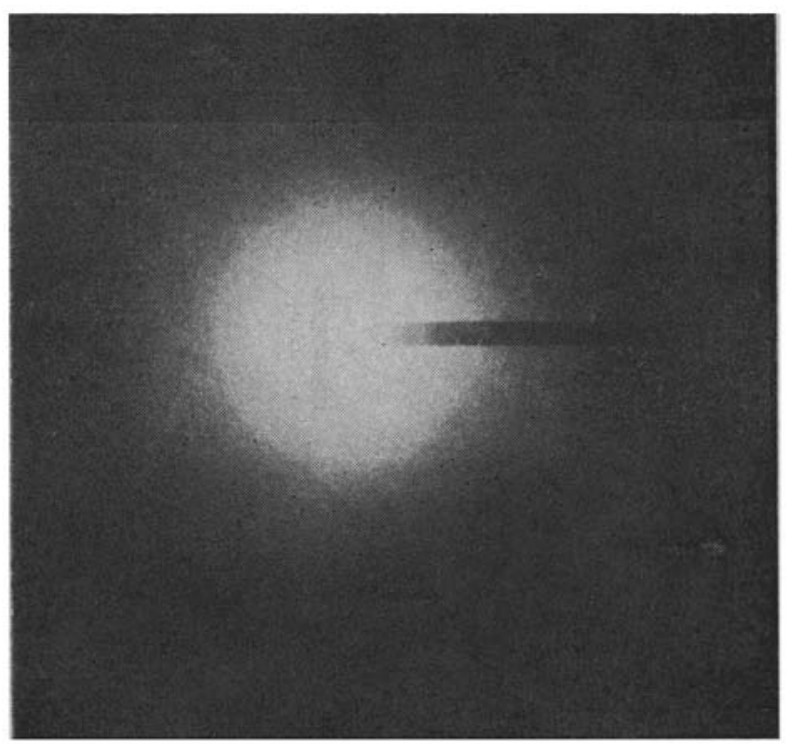

Figure 2. Electron diffraction micrograph of a-Si:H $\left(T_{\mathrm{s}}=580 \mathrm{~K}\right)$. 
gas. Before starting the discharge the system is evacuated to $10^{-2}$ torr and baked at $200^{\circ} \mathrm{C}$ for $12 \mathrm{hr}$. Typical deposition parameters which result in good quality films are listed below:

Substrate temperature $=580 \mathrm{~K}$, pressure $=1 \mathrm{torr}$; distance between anode and the screen $=2.5 \mathrm{~cm} ; \mathrm{DC}$ voltage $=460 \mathrm{~V}$ : discharge current $=6.3 \mathrm{~mA}$; power

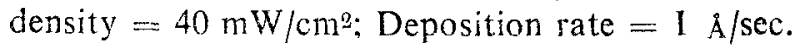

\section{$2 \cdot 2$ Structural characterization}

2.2a Electron microscopy: Copper or tungsten electron microscopic grids coated with carbon are used for deposition of amorphous silicon films of about $500 \AA$ thickness for transmission electron microscopy. An electron diffraction micrograph of one such sample deposited at $580 \mathrm{~K}$ is shown in figure 2 . It consists of diffused rings, which shows the amorphous nature of the films.

2.2b IR spectroscopy: a-Si:H samples of about $5000 \AA$ thickness are prepared on $\mathrm{KBr}$ pellets. Figure 3 shows the transmittance from 200 to $2500 \mathrm{~cm}^{-1}$ wavenumber, recorded on a Perkin Elmer 580 spectrophotometer. Curve $a$ is for a sample prepared at $300 \mathrm{~K}$ whereas curve $b$ is for samples prepared at $580 \mathrm{~K}$. samples deposited at $300 \mathrm{~K}$ have IR peaks at $2080,1000,890,850$ and $635 \mathrm{~cm}^{-1}$. In samples deposited at $580 \mathrm{~K}$, IR peaks at 1000,890 and $850 \mathrm{~cm}^{-1}$ are absent and a new peak appears at $2000 \mathrm{~cm}^{-1}$. The identification of these peaks is also given in figure 3. These results agree with the literature (Lucovsky et al 1979).

\section{$2 \cdot 3$ Measurements and results}

All the samples are heat-dried at $200^{\circ} \mathrm{C}$ for $2 \mathrm{hr}$ in a vacuum of $2 \times 10^{-5}$ torr before doing any electrical measurements.

2.3a Conductivity: de conductivity $(\sigma)$ measurements are done on samples on Corning 7059 glass substrates having chrome gold or nichrome contacts above or below the a-Si:H film in a coplanar configuration with a gap-spacing varying between $0.4 \mathrm{~mm}$ to $1 \mathrm{~cm}$. $\sigma$ is found to be independent of these parameters. Figure 4 shows $\sigma(T)$ of a-Si:H prepared at substrate temperatures $\left(T_{5}\right)=300,450$ and $580 \mathrm{~K} . \sigma(T)$ for an evaporated Si sample is also shown for comparison. Films prepared at 300 and $580 \mathrm{~K}$ have similar $\sigma$ at $300 \mathrm{~K} c(300 \mathrm{~K})=10^{-8} \mathrm{ohm}^{-1} \mathrm{~cm}^{-1}$, and have activation energies $(\triangle E)=0.62 \mathrm{e}_{\Lambda}$ and $0.7 \mathrm{eV}$ respectively whereas the samples prepared at $450 \mathrm{~K}$ have $\sigma(300 \mathrm{~K})$ $\because 4 \times 10^{-10} \mathrm{ohm}^{-1} \mathrm{~cm}^{-1}$ and $\Delta E=1 \mathrm{eV}$. These results are in qualitative agreement with the literature (Le Comber ef al 1972).

2. 3b Photocunluctivity: Films deposited at $300 \mathrm{~K}$ are not photoconducting. The photoconductivity $\left(\sigma_{\mathrm{ph}}\right)$ for films with $T_{\mathrm{s}}=450 \mathrm{~K}$ is $5 \times 10^{-19} \mathrm{ohm}^{-1} \mathrm{~cm}^{-1}$ and $10^{-4}$ ohm ${ }^{-1} \mathrm{~cm}^{-1}$ for $T_{\mathrm{s}} \ldots 580 \mathrm{~K}$. for white light of $5 \times 10^{14}$ photons $/ \mathrm{cm}^{2} / \mathrm{sec}^{2}$. The results of variation of photoconductivity as a function of temperature in the range $300 \mathrm{~K} \geqslant T \geqslant 200 \mathrm{~K}$ are shown in figure 5 for a sample prepared at $580 \mathrm{~K}$. The results of Wronski and Carlson (1977) are also shown for comparison. 


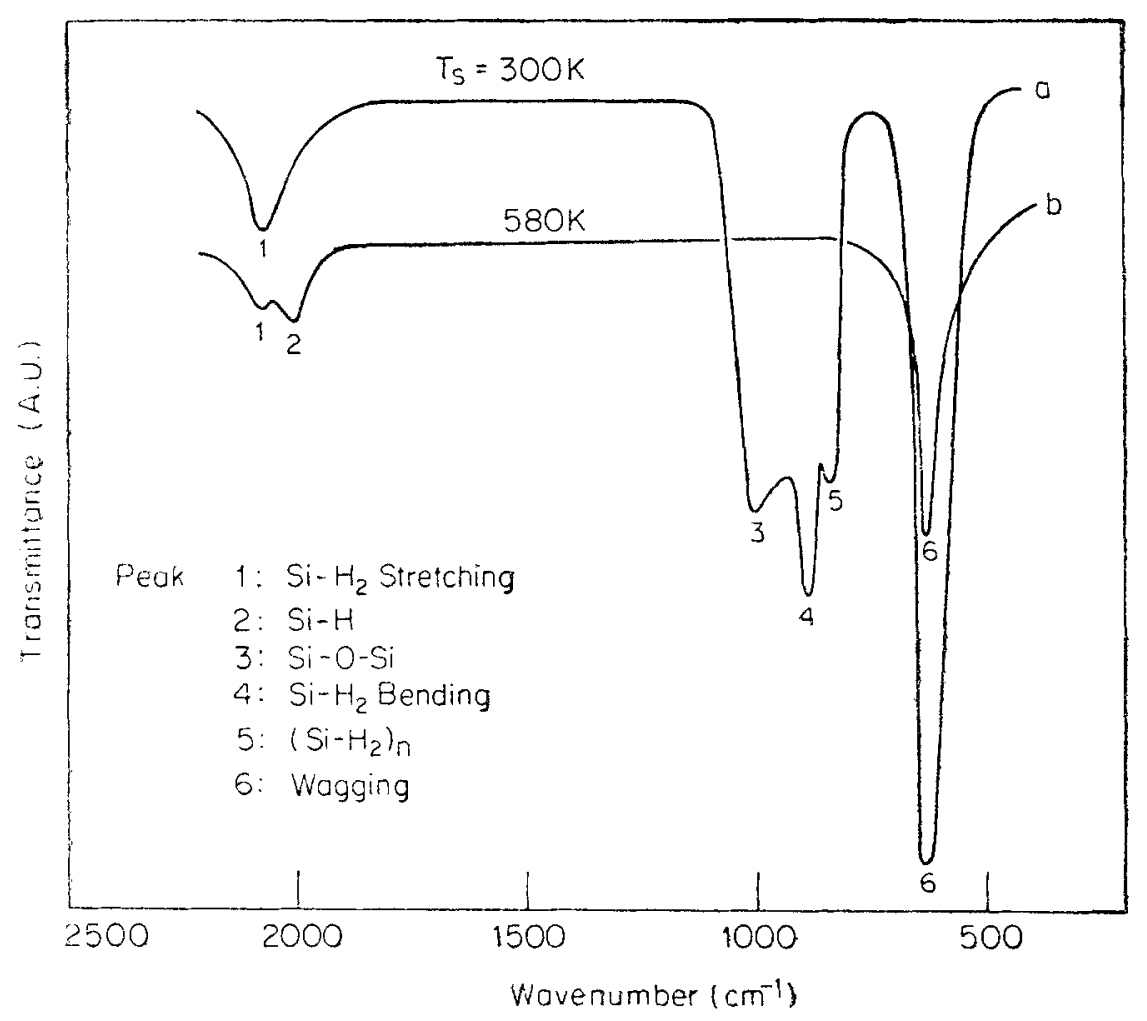

Figure 3. IR spectra of a-Si : $\mathrm{H}$.

2.3c Staebler-Wronski effect: Staebler and Wronski (1977) found that when samples of a-Si:H are exposed to AM1 light for about $4 \mathrm{hr}$ at $300 \mathrm{~K}$ in vacuum, $\sigma(300 \mathrm{~K})$ of the samples reduces by about 4 orders of magnitude. We have looked for this effect in our films $\left(T_{\mathrm{s}}=580 \mathrm{~K}\right)$ in air and as well as in vacuum. Figure 6 shows the results. Immediately after heat drying but before the light exposure the sample is in high conducting state with conductance $(G)$ at $300 \mathrm{~K}=7.5 \times 10^{-11} \mathrm{ohm}^{-1}$ and $\triangle E=0.62 \mathrm{eV}$. After exposure to AMI light for $4 \mathrm{hr}$ in air it gets transformed to a low conducting state with $G=$ $4.8 \times 10^{-12} \mathrm{ohm}^{-1}$ and $\triangle E=1 \mathrm{eV}$. Upon annealing to $175^{\circ} \mathrm{C}$ in vacuum the sample returns to its high conducting state The sample is then exposed to light (with the same intensity) in a vacuum of $2 \times 10^{-5}$ torr. Now $G$ changes from $7.5 \times 10^{-11} \mathrm{ohm}^{-1}$ to $2.4 \times 10^{-11} \mathrm{ohm}^{-1}$ and $\triangle E$ from $0.62 \mathrm{eV}$ to $0.7 \mathrm{eV}$. Thus we find that when our samples are exposed to light in vacuum, the effect is smaller. Further, in both cases the change in $G$ is much smaller for our films than reported by Staebler and Wronski (1977).

2.3d Photovoltaic effect: We have observed a photovoltaic effect in a-Si:H films having a sandwich structure. The bottom electrode is of nichrome of thickness $1 \mu \mathrm{m}$. The top electrode, through which the light is shone, is of gold of thickness $\approx 100 \AA$. The thickness of a-Si:H film is $1 \mu \mathrm{m}$. The typical area of such a 


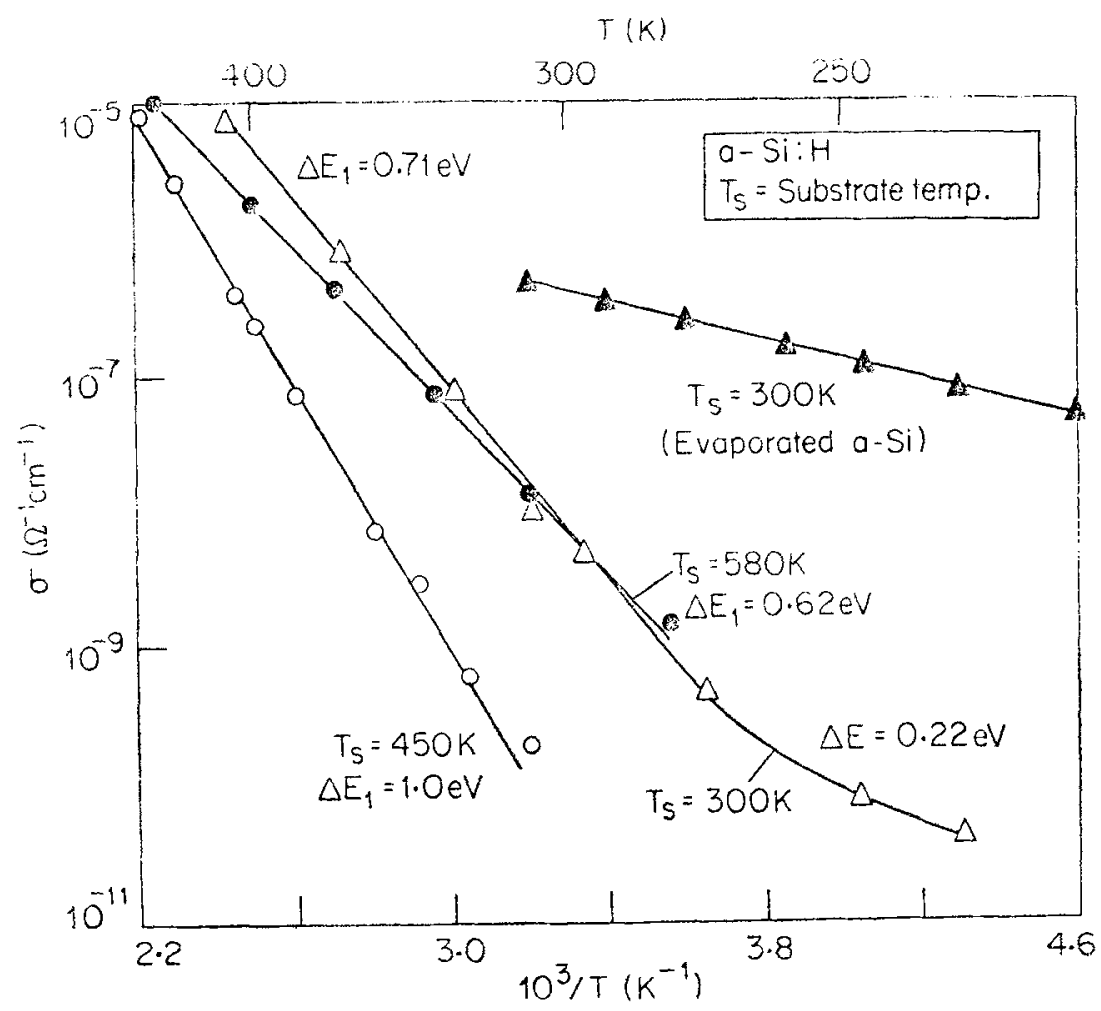

Figure 4. Variation of conductivity with temperature of a-Si:H.

device is $10^{-2} \mathrm{~cm}^{\prime 2}$. Typically, open circuit photovoltage $\left(V_{o c}\right)$ of a few hundred millivolts is obtained upon shining white light of photon flux $5 \times 10^{1^{4}}$ photons/ $\mathrm{cm}^{2} / \mathrm{sec}$. The short circuit current density is $1-3 \mathrm{~mA} / \mathrm{cm}^{2}$. The load characteristic of one such photovoltaic cell is shown in figure 7. The fill factor is about 0.35 and the calculated conversion efficiency $(\eta)$ is about $1 \%$.

\section{Discussion}

IR spectra deposited at $300 \mathrm{~K}$ have absorption peaks which correspond to $\mathrm{Si}_{-} \mathrm{H}_{2}$ (stretching), Si-O-Si, Si-H, (bending), $\left(\mathrm{Si}-\mathrm{H}_{2}\right)_{n}$ polymer chains, and $\mathrm{Si}-\mathrm{H}, \mathrm{Si}-\mathrm{H}_{2}, \mathrm{Si}-\mathrm{H}_{3}$ (wagging) modes as shown in figure 3 . In the sample deposited at $580 \mathrm{~K}$ the peak at $2000 \mathrm{~cm}^{-1}$ corresponds to $\mathrm{Si}-\mathrm{H}$ (stretching). Thus it is clear that in films prepared at $580 \mathrm{~K}$ hydrogen is present mostly as monohydride. Also, the intensity of IR peaks is reduced in the sample deposited at $580 \mathrm{~K}$. This shows that hydrogen concentration in samples deposited at $580 \mathrm{~K}$ is lower than the ones deposited at room temperature, in agreement with the published work (Lucovsky et at 1979).

Figure 4 shows that $\sigma$ is thermally activated with two activation energies for the film prepared at $300 \mathrm{~K}$. These might arise from two conduction mechanisms. In the temperature range $420 \mathrm{~K}-300 \mathrm{~K}$ the band to band conduction seems 
to dominate in which case $\Delta E$ is large $(0.7 \mathrm{eV})$ whereas conduction in the extended band tails can explain the low $\Delta E(0.3 \mathrm{eV})$ in the temperature range $300 \mathrm{~K}$ to $230 \mathrm{~K}$. The samples prepared at higher substrate temperature have a single activation energy, corresponding to band conduction.

Samples prepared at high $T_{S}$ are found to be highly photoconducting. In these samples IR spectroscopy shows that hydrogen is present mostly as monohydrides. Since the conduction in the band tails is absent in these films, we might argue that the presence of monohydrides gives films having a lesser number of gap states resulting in the high photoconductivity; although the exact role played by such bonds is still far from clear. The thermoelectric power measurements on our samples (Shailendra Kumar 1981) show that our samples are $n$-type. The $\sigma_{\mathrm{ph}}(T)$ curve agrees qualitatively with that obtained on undoped films by Wronski and Carlson (1977) (see figure 5) whose films are also of $n$-type. The activation energy of the low $T$ part of the plot of $\sigma_{\mathrm{ph}}$ (T) can be used to estimate the depth of recombination centres. In our samples it is about $0.4 \mathrm{eV}$ below the conduction band. This should be compared with $0.25 \mathrm{eV}$ obtained by Wronski and Carlson (1977).

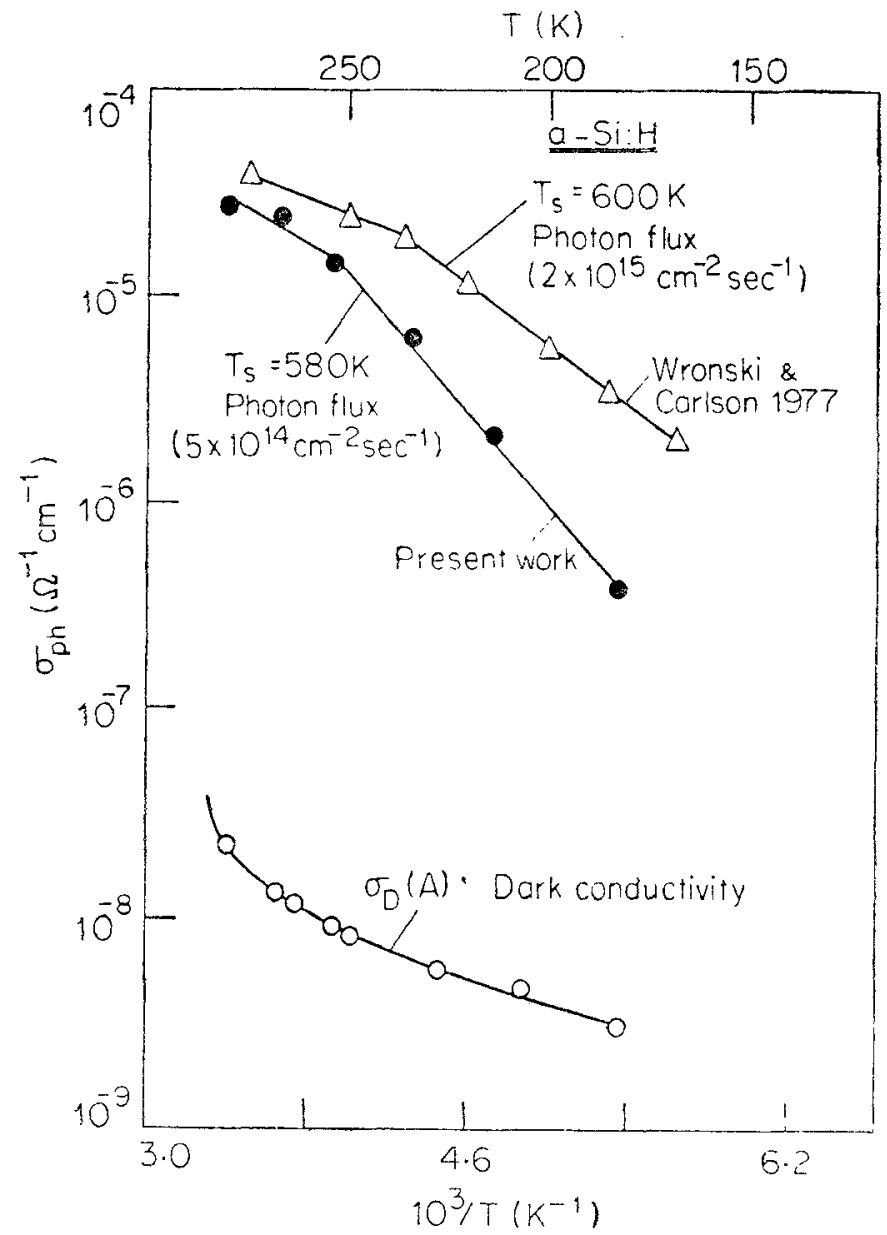

Hgure 5. Variation of photoconductivity with temperature of a-Si:H 


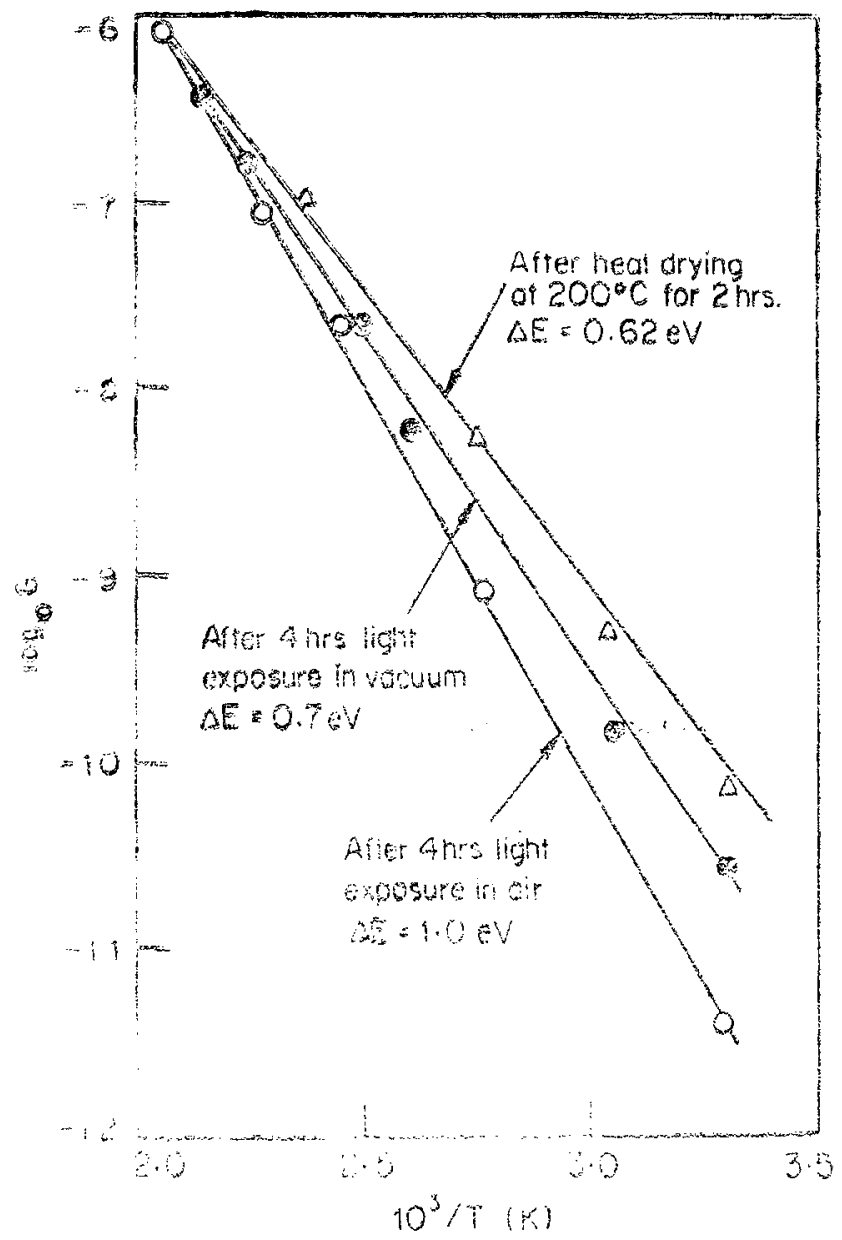

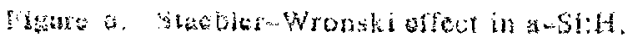

Theo inchunisms have been proposed (Staebler and Wronski 1977) to explain the lighteinduced eflects in a-Si films: (i) Pxistence of band bending at the Wilm substrate interface, (ii) cxistence of band bending at film-air interface, (iii) creation of the traps in the bulk of the film due to photo-structural chanses. In the first two cases it is assumed that a layer of positive charge at the surface of interface in the unexposed films gives rise to surface or interface acoumulation layers of higher conductivity. Upon cxposure, the photoclectrons neutralize these charges thus removing the band bending; the conductivity in this wase would be the true bulk conductivity. However, this band bending is not always present. Comparison of the field effect on the film substrate interface and on the top by Guha et al (1980) has indicated that band bending is negligible in their films. The third explanation invokes the creation of new states when the sample is exposed to light. This has been shown to take place in the ase of Schottky barriers fabricated on a-Si:H, in which the series resistance increases upon exposure to light (Jousse ef al 1980). In our casc the change in $\sigma$ 


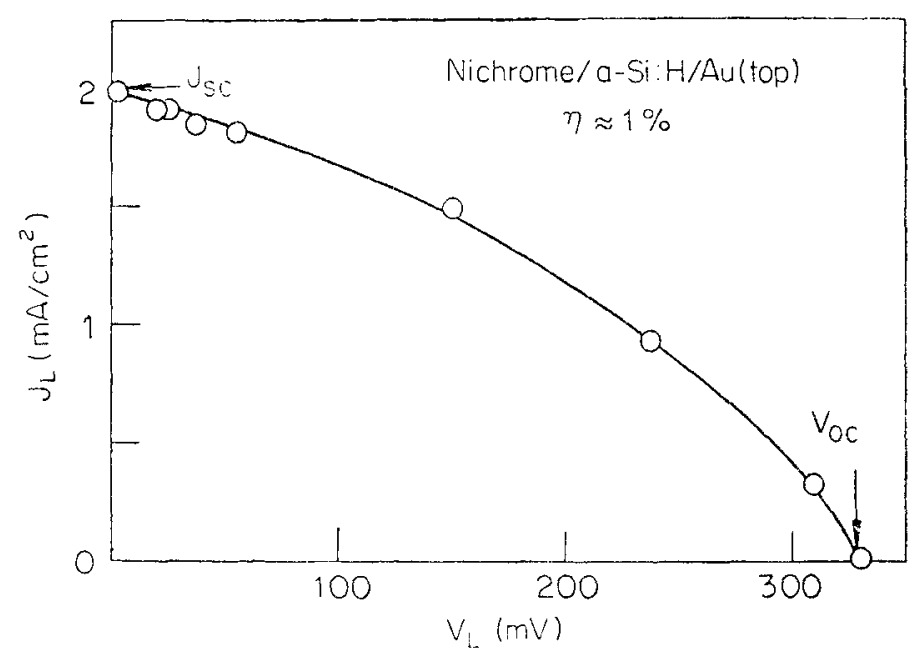

Figure 7. Load characteristic of $\mathrm{NiCr} / \mathrm{s}-\mathrm{Si}: \mathrm{H} / \mathrm{Au}$ (top) photovoltaic cell.

upon exposure to light is smaller in vacuum than in air. This shows that the surface states do play a role. However, at present it is difficult to say if any or all of the above mechanisms are operative in our films. Further, although the Staebler-Wronski effect in our films is much smaller than is usually seen by others using argon silane mixture (Staebler and Wronski. 1977; Tanilian et al 1978), it is of the same order of magnitude as reported by Guha et al 1981 who used a mixture of $10 \% \mathrm{SiH}_{4}$ in hydrogen. Thus it appears that the variation in composition of gas mixture alone cannot fully explain the discrepancy. Other preparation conditions, (e.g. the glow discharge conditions) might be responsible for different quality films obtained by different workers.

The conversion efficiency of our devices is about $1 \%$, which appears to be smaller than the best value of $5.5 \%$ reported in the literature (Carlson 1977). The efficiency of a photovoltaic device ciepends upon various factors such as substrate material, barrier metal, etc. Further, the high efficiency devices prepared by others have anti-reflection coating at the top to avoid the reflection of light from the surface. We have not yet strived to improve these conditions in our case. But the stability of our films against light exposure might be taken as an indication that if these factors are improved, we might be able to improve the efficiency of our photovoltaic device considerably. An exhaustive study for optimization of all these parameters is in progress.

\section{Acknowledgements}

We acknowledge the valuable suggestions given by Professor T M Srinivasan irom time to time during the course of this work. The financial assistance from the Department of Science and Tichnology, New Delhi is also acknowledged. 


\section{References}

Brodsky M H, Frısch Li A and Ziegler J F 1977 Appl. Phys. Lett. $30 j 01$

Carlson DE 1977 IEEE Trans. Electr. Dev. ED-24 494

Fritzsche H, Tsai C C and Persans P 1978 Solid State Technol. 2155

Guha S, Narsimian K L, Navkandelwala R K and Pietruszko S M $1980 \mathrm{App}$. Phys. Lett. 37572

Guha S, Narsimhan K L and Pietruszko S M $1981 \mathrm{~J}$. Appl. Phys. (to appear)

Jousse D, Viktorovitch P, Vieux Rochaz L and Chenevas Paule A 1980 J. Non Cryst. Solids 35-36 767

Le Comber P G, Madan A and Spear W E 1972 J. Non Cryst. Solids 11219

Lucovsky G, Namanich R J and Knights J C 1979 Phys. Rev. B19 2064

Shailendra Kumar 1981 (to be published)

Spear W E and Le Comber P G 1975 Solid State Commun. 171193

Staebler D L and Wronski C R 1977 Appl. phys. Lett. 31292

Tanielian M, Fritzsche H, Tsai C C and Symbalisty E 1978 Appl. Phys. Lett. 33353

Wronski C R and Carlson D E 1977 Proc. 7th International Conf. Amorphous and liquid semiconductors (ed) W E Spear (Edinburgh: Univ. of Dundee) P. 452

Yote added in proof

Using palladium as the top contact, we have recently been able to get $\eta=4.5 \%$ for $\mathrm{NiCr} / a-$ $\mathrm{Si}: \mathrm{H} / \mathrm{Pd}$ Schottky barrier solar cells, without antireflection coating. 